\title{
Teaching prosody in German as foreign language
}

\section{Ulla Hirschfeld and Jürgen Trouvain}

\section{Introduction}

The "sound of a language", which is primarily transmitted by prosodic features, does not just convey the content of an utterance, but also other important communicative information. It marks the emotional state of the speaker and it can have the effect of being calming, detesting, encouraging, warm, cold, intimate or strange. Moreover, the individual way of speaking is a key feature of a speaker's personality, an audible "business card". From the foreign accent and other features native speakers deduce the educational status, the social affiliation, the degree of intelligence and even certain traits of the individual character (cf. Hirschfeld 1994). For these reasons prosodic features should be taught in the first line when teaching pronunciation.

What can be expected from "theory" on prosodic structure and realisation of prosody? What can be transmitted to teachers of German as a foreign language (henceforth $\mathrm{DaF}$ for Deutsch als Fremdsprache)? In which way can it be made clear? Theories about what prosody exactly is and how it can be described are not as simple as a teacher may wish, because the rules how to realise prosody are not as clear-cut as the rules how to realise the sounds of a word. Different conditions determine the correctness and the acceptability of the prosody of an utterance such as the communicative situation and the text type. Seen from the teachers' perspective, researchers have not always a good knowledge of what teachers are interested in. A high quality in teaching of prosody requires a fruitful dialogue between researchers and teachers. The goal of this article is to present how concepts from "theory" can be applied and integrated into foreign language teaching illustrated with examples of German as target language. 


\section{Typology of deviant forms on the prosodic level}

Pronunciation and phonetics in German language teaching have been ignored for a long time (and some popular text books that include practical material still do) but a change can be observed over the last 15 years. However, exercises with the focus on prosody are rare apart from those dealing with lexical stress. If pronunciation is part of a language teaching book then often the topic is reduced to segmental phenomena such as the "ich-Laut" $[c]$, the glottal fricative $[h]$ or the rounded front vowels [y: Y $\emptyset: \propto]$. Seldom considered are other consonants and vowels such as schwa [ə]. This is striking because the schwa is by far the most frequent vowel in German (cf. Kohler 1995: 222), and clearly the most frequent vowel in unstressed syllables playing a vital role in the rhythmic alternation of stressedunstressed patterns. Although in Figure 1 the vowels are presented in their underlying form, the very common elisions of schwa in endings like <-en>, $<-$ el $>,<-e m>$ in German represent a problem for learners with respect to vowel quality (replaced by a full vowel such as $[\varepsilon]$ ) as well as the rhythmic patterns.

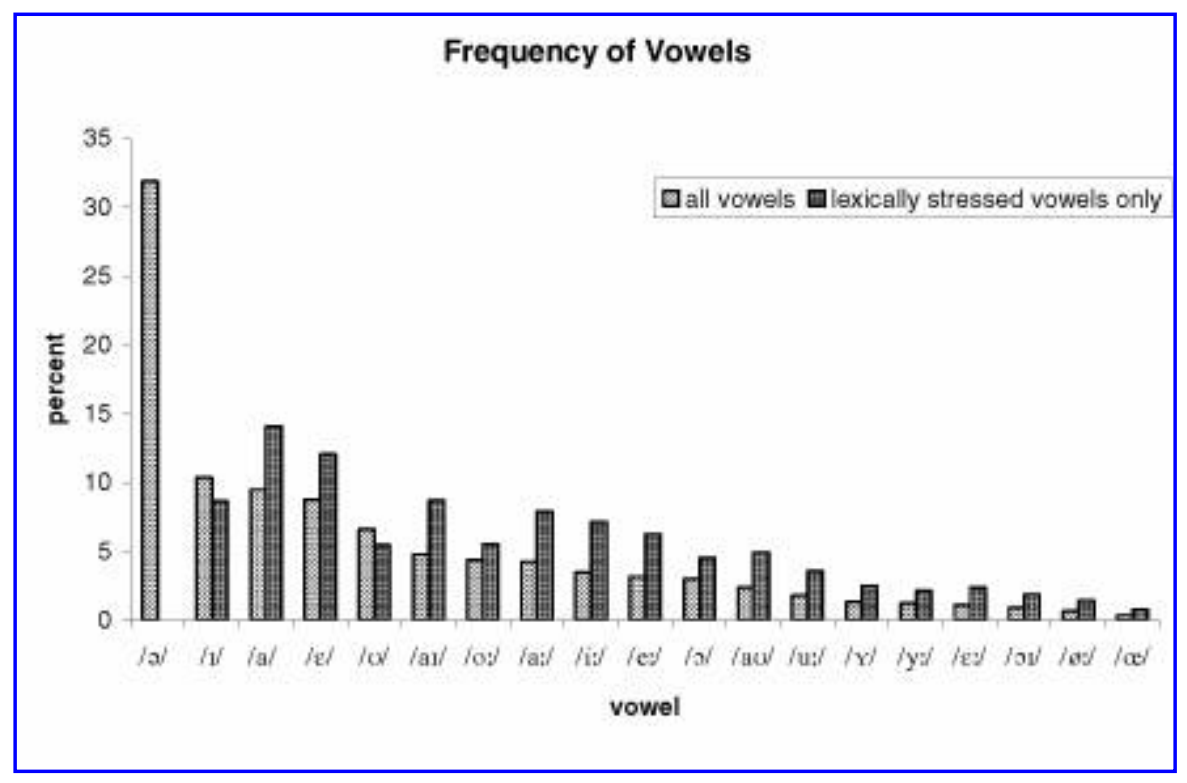

Figure 1. Occurences of vowels in a German speech corpus in percent, sorted by frequency, based on the data by Kohler (1995: 222). 
In addition, many phenomena responsible for a foreign accent in German are of a supra-segmental or prosodic nature. Take for example a study with learners of German with different L1 who produced the sentence "Es regnet." ("It is raining."). When the accentuation fell on the last syllable of the verb (accentuation pattern "es regNET") more than half of the German listeners (of various age) were unable to recognise the sentence correctly. In the correct pattern "es REGnet" only $5 \%$ of the listeners failed to get the message. Most listeners understood for "es regNET" sentences like "Ist sehr nett." ("(It) is very nice.") or "Es ist nett?" ("It is nice?"). The fact that declaratives as well as questions were understood shows that the melodic shape of the utterance was not clear and also that the segmental structure had been adapted to the suprasegmental structure. Here, the location of the accentuated vowels plays a decisive role. Too many interruptions in the form of pauses within an utterance led to further difficulties. Suprasegmental deviations in combination with segmental mistakes caused a complete incomprehensibility for many listeners in this study (cf. Hirschfeld 1994: $102 \mathrm{ff}$.)

Although there is a great individual range of errors, some problems can be observed in groups of learners with a heterogeneous language background. The list in Table 1 summarises possible errors attributable to the prosodic levels of prominence (of words and utterances, respectively), pitch contour and phrasing.

Table 1. Problems of L2 speech on different prosodic levels.

\section{lexical stress}

phonological 1. on the wrong syllable

phonetic

2. lengthening of short stressed vowels

phonetic

3. too little contrast when realising stressed vs. unstressed syllables

phonetic 4. lack of segmental reductions in unstressed syllables

phonetic 5. melodic deviations in stressed and/or unstressed syllables (cf. melodic contour)

phonetic 6. over-strong secondary stresses in longer words, esp. compound words 
Table 1. (continued)

pitch accents

phonological 1. too many pitch accents

phonological 2. accent on the wrong word/s

phonetic 3. incorrect or too strong secondary pitch accents

phonetic 4. over-lengthening of pitch accented short vowels

phonetic 5. too little contrast when realising pitch accented vs. unaccented syllables

phonetic 6. lack of segmental reductions in unaccented syllables

melodic contour (pitch range, pitch accent realisation, end of utterances)

phonetic 1. melodic deviations in stressed and/or unstressed syllables

phonological 2. wrong melodic contour at the end of utterances

pauses and phrasing structure

phonological 1. too many pauses

phonological 2. pauses at wrong locations

phonetic 3. too long pauses

\section{L1 influences}

Some features of German prosody nearly always lead to difficulties for language learners: typical melodic contours (e.g. the accomplishing of the final low at the end of utterances), assignment and production of lexical stress, structuring and realisation of rhythm. Depending on their first language or prior acquired foreign languages, speakers exhibit different problems with their German L2 prosody. The examples in Table 2 illustrate typical deviations for some languages.

Additional types of deviation are described in contrastive studies in Hirschfeld et al. (2002 ff.) where a survey of 40 languages is given.

Attention must be paid to the fact that for many language learners German is often the second foreign language after English, and sometimes even the third or fourth foreign language. Thus, interferences from prior acquired foreign languages must also be expected. 
Table 2. Typical deviant prosodic forms for L2 German speakers with various first languages.

\begin{tabular}{|c|c|c|c|c|c|c|}
\hline phonological deviations & 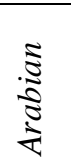 & 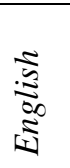 & 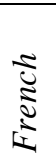 & 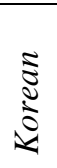 & 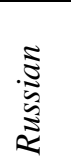 & $\begin{array}{l}\frac{\tilde{a}}{\tilde{\Xi}} \\
\text { जी }\end{array}$ \\
\hline rules of lexical stress & $\mathrm{x}$ & $\mathrm{x}$ & $\mathrm{x}$ & $\mathrm{x}$ & $\mathrm{x}$ & $\mathrm{x}$ \\
\hline $\begin{array}{l}\text { length and quality of vow- } \\
\text { els in stressed syllables }\end{array}$ & $\mathrm{x}$ & $\mathrm{x}$ & $\mathrm{x}$ & $\mathrm{x}$ & $\mathrm{x}$ & $\mathrm{X}$ \\
\hline \multicolumn{7}{|l|}{ phonetic deviations } \\
\hline $\begin{array}{l}\text { contrast stressed- } \\
\text { unstressed }\end{array}$ & $\mathrm{x}$ & & $\mathrm{X}$ & $\mathrm{x}$ & & $\mathrm{X}$ \\
\hline $\begin{array}{l}\text { insufficient reduction of } \\
\text { unstressed syllables }\end{array}$ & $\mathrm{x}$ & & $\mathrm{X}$ & $\mathrm{x}$ & & $\mathrm{X}$ \\
\hline $\begin{array}{l}\text { over-strong reduction of } \\
\text { unstressed syllables }\end{array}$ & & $\mathrm{x}$ & & & $\mathrm{x}$ & \\
\hline $\begin{array}{l}\text { accent marking predomi- } \\
\text { nantly by intensity }\end{array}$ & $\mathrm{x}$ & & & $\mathrm{x}$ & & $\mathrm{X}$ \\
\hline $\begin{array}{l}\text { pitch contour in utterance- } \\
\text { final low }\end{array}$ & $\mathrm{x}$ & & & $\mathrm{x}$ & $\mathrm{x}$ & $\mathrm{X}$ \\
\hline
\end{tabular}

\section{Phonetics in textbooks, learning materials and foreign language teaching}

In teaching German as a foreign language pronunciation training traditionally plays only a minor role, if there is any a training at all (cf. Hirschfeld 2003: 193 f.). The following sub-sections present an impressionistic analysis of the various factors and processes in current German language teaching practice.

\subsection{Teaching and learning materials and methods}

In teaching and learning materials and methods there is no satisfactory choice with respect to the exercises, the mix of methods, and the number of exercises. There is insufficient additional material for the particular needs of different learner groups which may differ in several respects such as: 
- the learners' first language(s)

- their proficiency level in the foreign language

- the age of the learner

- the learning goals

The methods also have to differ in aspects such as

- the teaching traditions they are familiar with

- the group characteristics (linguistically homogeneous vs. heterogeneous; group size)

- teaching situation (time; location; technical equipment).

\subsection{Research on pronunciation training}

There are still too few published research studies on didactic and methodological issues in pronunciation teaching. This explains why the analysis of research results is still not an integral part of teachers' education, especially at universities.

\subsection{Consideration of research in learning materials}

The authors of textbooks do not usually take publications in phonetic research into consideration, e.g. studies in contrastive phonetics, investigations of norms and variation in standard German, or studies dealing with functions and effects of phonetic features in intercultural communication.

\subsection{Teachers}

The many peculiarities that define the teaching and learning of pronunciation compared to other skills are not considered in a differentiated way. Instead of dealing with pronunciation problems with individual and/or L1 causes, many teachers give up before they start, with the argument that the possible effect does not justify the effort. There is a widespread opinion that phonetics is a luxury. This attitude leads to the Cinderella role of pronunciation in teaching: Phonetics as the foundation of speaking and hearing in spontaneous conversation as well as of learning alphabet-based writing systems is simply ignored. Even though the situation has improved some- 
what with regard to speech sounds (and lexical stress) in the last 15 years, the teaching of prosody is still completely unsatisfactory.

A second problem is that phonologically relevant prosodic and segmental characteristics and standards of pronunciation are not just transmitted by means of appropriate exercises but also by the teacher's own speech production. In foreign language training, learners orientate themselves to their teachers. Thus, the teacher's pronunciation plays an important role because it functions as a model (Dieling and Hirschfeld 2000: 19ff.). Many teachers of German are a bad model because they speak with their non-German accent or with a regional accent. Therefore it is important to make the teaching material function as a model. The teachers in question should be aware and admit to their accented speech.

\subsection{Training of teachers}

In teachers' training, the mediation of the phonetic/phonological and the pedagogical basics is not taught sufficiently. The consequence is that many teachers feel insecure about how to introduce phonetic forms and how to make learners aware of them, how to correct deviant forms and how to help them to automate correct forms. The teachers must be prepared during all training phases

- to determine the use of the didactic methods in class, but also for individual teaching, i.e. the development of concepts of exercises for listening and speaking,

- to recognise prosodic (and segmental) deviant forms, to point out the deviant forms and to correct them, ideally in an emphatic but motivating and effective way,

- to select and invent appropriate exercises, and to take care of a sufficient level of automation,

- to mediate rules and knowledge (differentiating quantity and methods for different groups of learners),

- to accept and understand their role as a model of language and speech (with the consequences for their respective foreign or regional accents). 
These requirements are much more than those we can observe in classrooms nowadays. In the next two sections various types of exercises are presented followed by concrete examples applied in university classes.

\section{Types of exercises}

Many teachers of German assume that prosody is acquired by listening and imitation ("parrot method"). Most teaching materials also focus on imitation exercises. However, few learners are able to produce acceptable imitations. Especially teenagers and adult learners exhibit problems that can be attributed to various causes. Therefore, the types of exercises for the development of the perception and production skills must be carefully selected and their timing carefully organised.

The first step with listening exercises does not aim at understanding the content but at phonological and phonetic listening. The focus of phonological or phonematic listening is to distinguish and identify elements which differentiate meaning:

a. ein FACH - EINfach (English "a compartment"/ "a subject" - "simple")

b. Ja? - Ja! (English "Yes?"/ "Really?"/ -“Yes!")

Phonological listening is the fundament to the further processing and interpretation of spoken utterances. The next step, the phonetic listening, goes beyond the simple differentation of meaning: the perception of phonetic variants which occur frequently in daily situations is required, e.g. the speech melody in accented syllables or the lengthening of pauses. Here, the common practice of providing audio examples and asking learners to "listen carefully" is not sufficient. Teachers as well as learners need to know where difficulties are likely to occur. This knowledge is only possible when the results of the listening are monitored. There are several ways of doing this ranging from marking syllables and words to transcribing; for quick feedback hand signals can be used.

Controllable listening exercises with minimal pairs are also recommended. These are easily prepared, using first and second names or geographical names. In order to discriminate, two or three names can given, e.g. 
a. Which town is stressed on the last syllable? Luzern - Salzburg, Berlin - Halle - München

b. Which name does contain a long vowel in the stressed syllable? Müller - Mühler, Mehler - Meller - Möller

For an identification task the teacher gives an example in advance, e.g.

a. Which syllable is lexically stressed? The first, the second, the third or the last?

Mönchengladbach

b. Is the stressed vowel a long vowel or a short vowel?

Möhler

The learner can even practise this type of listening exercises without a teacher if appropriate software is at hand such as "Phonothek interaktiv" (Hirschfeld and Stock 2000).

It is recommended that exercises for listening are linked to those for speaking by also using the listening material for imitating, reading aloud, variation and combination. Furthermore, monologue and dialogue texts, word lists and grammar exercises taken from the text book can be used as a basis for phonetic exercises - they all contain examples which are appropriate for practising. Examples can be used for visual highlighting, for word search, for sorting, listening, humming, articulating and reading aloud. They can be used in different contexts and they can also be accompanied by gestures. Pauses, melodic contours and accent patterns can be marked in texts, either after listening or from memory. Learners can articulate synchronously with the speakers of the audio examples. It is important that different learner strategies are stimulated and that not always the same type of exercises is offered. Exercises should vary and the requirements should continuously increase. Exercises for automation should start with rhythmic-melodic units larger than a word - the practice of single sounds and the articulation of words in isolation should be restricted to the first phase and the correction phase.

\subsection{Methodological steps}

We recommend a methodological procedure that has been validated across a wide range of teaching situations (cf. Hirschfeld 2003: 202): 
1. introduction of the topic, e.g. with a comprehension text

2. listening control, i.e. differentiate (compare) and identify (recognise) prosodic features

3. imitation attempts, individually and in chorus in order to rehearse anonymously

4. correction of deviant forms, to make the learners aware of the critical phonetic features

5. repeated listening control

6. further imitation attempts with feedback

7. automation by repeating, reading, variation of speaking style

\subsection{Typology of exercises}

Providing a good mix of methods includes the provision of different types of exercises. In Dieling and Hirschfeld (2000: $47 \mathrm{ff}$.) various types of exercises are suggested. The most important ones are:

- listening exercises

- preparatory listening exercises as warm-up exercises: e.g. first names in rhyming, proverbs, texts

- identification: e.g. recognising the stressed syllable in a first name (Michael, Michaela, Christian, Christiane)

- discrimination: e.g. compare stress position in first names $(P e$ ter $=$ Petra, Robert \# Roberta)

- applied listening: e.g. first names in texts

- imitation exercises

- creative production exercises

- alter, add, combine linguistic elements

- in combination with work on grammar and vocabulary

- applied production exercises

- read aloud, oral presentation

- free speech

- acting in scenes 


\subsection{Central points for exercises in prosody}

The focus of exercises should differ according to the learners' first language. Native speakers of tone languages have greater and more complex difficulties than native speakers of Germanic languages (other than German). The following topics are fundamental for the comprehension of German; they should be given a central role among the phonetic exercises:

- lexical stress

- stress assignment (application of stress rules)

- vowel length in stressed syllables (long vs. short)

- contrast of stressed vs. unstressed syllables

- rhythm

- accentuation at utterance level

- alternation of stressed - unstressed syllables in rhythmic groups

- schwa

- realisation of schwa-syllables, especially elision of schwa in word-endings - as an important element of rhythmic structure

- pauses and phrase structuring

- typical melodic contours

- fall-rise contour in yes/no-questions and contact-eliciting or very friendly utterances

- rise-fall contour in terminal declarative utterances

- (extreme) final low at the end of utterances

\section{Examples of exercises}

In this section we intend to show some examples of exercises that can be applied in almost every pronunciation lesson and which can easily be varied. The two most important features are:

1. Apart from the phonetic topic there is always a content theme such as location names or clothing. The exercises in sections 6.1 and 6.2 can be individually modified: instead of town names one can practise the stress patterns with food terms, hobbies, names of bus stations etc. These content-oriented exercises make them interesting for the learners and pro- 
vide a better memorization of the phonological pattern as well as the vocabulary.

2. Each exercise consists of several steps which elicit and support the activity of the learner. The exercises are not restricted to a few isolated chance collection of words and sentences which have to be heard and repeated. The structure of exercises proposed here makes a high degree of automation possible because further steps can be added continuously, i.e. the same material can be practised with different tasks.

The following exercises are taken from Hirschfeld and Reinke (1997) where further practical suggestions are given.

\subsection{Lexical stress}

Step 1: Listen to the town names and assign them to the stress patterns.

Berlin, Hannover, Hamburg, Magdeburg, Neuruppin ...

\begin{tabular}{|c|c|c|c|c|}
\hline 1. & 2. & 3. & 4. & \\
\hline$\bullet \bullet$ & $\bullet$ & $\bullet \bullet \bullet$ & $\bullet$ & $\bullet \bullet$ \\
\hline
\end{tabular}

Step 2: Listen again and repeat.

Step 3: Can you find other German towns that fit to these patterns?

Step 4: Draw stress patterns for towns in your own language.

Step 5: Practice exercise: plan a journey in towns with bi-syllabic names and stress on the first (second) syllable.

\subsection{Vowel length}

Step 1: Listen to example words (Mantel, Schal, Hose, Socke), show with your hands whether the stressed vowel is long or short.

Step 2: Write down (ten) pieces of clothing below the appropriate heading short or long in a two column-table, depending on the length of the stressed vowel. 


\begin{tabular}{|l|l|}
\hline short & long \\
\hline Hemd & Hose \\
Rock & Schal \\
$\ldots$ & $\ldots$ \\
\hline
\end{tabular}

Step 3: With this table, the learners have to find out by themselves what the spelling rules are that tell you whether it is a long or a short vowel. These spelling-to-sound rules for the vowels should be summarised by the teacher.

Step 4: For practice the learners are asked to "pack a suitcase for a short trip, taking only clothes that have a short vowel!". Alternatively, or as an exercise after the "short-vowel-journey" a "long-voweljourney" can be offered.

\subsection{Melody and phrasing}

Step 1: Have a look at the following lines. The sentences consist of the same words in the same order.

$\begin{array}{lllll}1 & \text { PAULA } & \text { WILL } & \text { PAUL } & \text { NICHT } \\ 2 & \text { PAULA } & \text { WILL } & \text { PAUL } & \text { NICHT } \\ 3 & \text { PAULA } & \text { WILL } & \text { PAUL } & \text { NICHT } \\ 4 & \text { PAULA } & \text { WILL } & \text { PAUL } & \text { NICHT } \\ 5 & \text { PAULA } & \text { WILL } & \text { PAUL } & \text { NICHT }\end{array}$

Step 2: Listen to the examples and add the punctuation signs.

It should be done step by step, example by example, week by week.

You end up with a list like this one:

1 PAULA WILL PAUL NICHT.

2 PAULA WILL, PAUL NICHT.

3 PAULA WILL? PAUL NICHT.

4 PAULA, WILL PAUL NICHT?

5 PAULA WILL PAUL, NICHT? 
Step 3: Find further examples and add the following punctuation signs between the words: ? ! , ; . ,"

Step 4: Compare your results with your partner's.

Step 5: Read the different variants aloud. Your partner should correct your performance.

\subsection{Sentence or (pitch) accent}

Step 1: Listen to the examples and underline the accented words. The list will look like this:

$\begin{array}{lllll}1 & \text { PAULA } & \text { WILL } & \text { PAUL } & \text { NICHT. } \\ 2 & \text { PAULA } & \text { WILL } & \text { PAUL } & \text { NICHT. } \\ 3 & \text { PAULA } & \text { WILL } & \text { PAUL } & \text { NICHT. } \\ 4 & \text { PAULA } & \text { WILL } & \text { PAUL } & \text { NICHT. }\end{array}$

Step 2: What are the meanings of the variants? Can you imagine a situation where "Paula" is in the focus of the utterance?

Step 3: Read the different sentences aloud. This can be done as a partner exercise.

\subsection{Schwa}

Step 1: The letter $<\mathrm{e}>$ is the most frequent letter in German. It corresponds sometimes to [e:], [E], or is part of [aI][or][i:]. But in many occasions the $<\mathrm{e}>$ has a different pronunciation as in the words hatte, rede, sage, liebe. Can you produce this e-sound in isolation?

Step 2: What are the corresponding infinitive and plural forms? What happens to the written $<\mathrm{e}>$ in hatten, reden, sagen, lieben $n$ ?

Step 3: Look at the followig word stems: red-, sag-, lieb-. What does this verb sound like in the first person singular compared to the first person plural? ['re:də] vs. ['re:dn]

Step 4: Listen to the following three words: Härte, härter, Hertha. What is the difference? Can you hear the difference between the unstressed [a] and the "vocalized r"? 
Step 5: What do the comparative forms of the adjective klein sound like? Fill in Eine klein-Schwester, Ein klein-Bruder.

Step 6: Mark in the text where an <e> represents a schwa, a deleted schwa or where $<\mathrm{e}>$ stands for a "vocalized $r$ ".

\section{Methodological recommendations}

The most important features of prosody must be made clear to both learners and teachers in an adequate way. What is the role of the teacher? How are teachers to be convinced that prosody is important? How are teachers to be taught?

Here is a summary list of the requirements for foreign-language teachers (cf. Hirschfeld 2003: 213 f.):

1. motivate

2. visualise (e.g. body movements)

3. show knowledge of phonetic characteristics

4. make learners aware of deviant forms

5. check performance in listening exercises

6. provide interesting, non-routine and creative fun exercises

7. provide enough exercises for a sufficient level of automation

8. provide exercises: better frequent $\&$ short than infrequent $\&$ long

9. focus on rhythmic-melodic units (i.e. larger than just one word)

10. integrate exercises into situations and context

11. combine exercises with work on grammar and vocabulary

In our view, teachers must be willing and able to recognise, to explain, and to correct the most serious problems in the area of prosody and pronunciation in general and also to give adequate feedback. They must know rules, characteristics, and the structures of the native language/s of their language learners. They have to apply multiple methods, since the "parrot method" as the most commonly practised method is not sufficient.

\section{Conclusion}

This article aimed to describe the state-of-the-art of prosody and pronunciation teaching in DaF. Despite some progress in the last few decades, we can 
still identify enormous deficits. These deficits concern the practice, i.e. the knowledge of teachers and the teaching materials available, as well as the theory, i.e. research in second language acquisition that does not take the practicalities of teaching in consideration. An understanding of both theory and practice is necessary to reduce these deficits. We hope that this article can contribute to this goal by showing the most important problems but also by presenting some practical solutions.

There is clearly much to do in order to develop satisfactory methods of teaching prosody. This concerns the diagnosis of phonetic, especially prosodic deviations, the application of exercises, and of course a measure for comparing levels of prosodic mastery. Another unsolved question that requires intensive discussion and research is how to assess various teaching methods. Is there any way to test learners' progress when teachers integrate prosody into their pronunciation teaching? What is the impact of prosody training? Is there an impact of prosody training in the first place? To answer those questions multiple factors must be taken into account such as the learners' L1, the group size or the learners' proficiency level in the foreign language. However, the reality in classrooms does usually not allow the control of all those factors.

Nevertheless, experience in teaching practice has clearly shown that a systematic training of prosodic elements raises the degree of intelligibility in the foreign language (Hirschfeld 1994; Missaglia this volume). At the same time the pronunciation of vowels and consonants improves because the learners are now sensitive to features also relevant for segmental structure such as duration and articulatory tension, e.g. for vowel oppositions like $\left[i-I, U i-U, O^{\prime}-\supset\right]$ and so forth. Therefore we think that teaching prosody goes hand in hand with teaching the pronunciation of sound segments.

\section{References}

Dieling, Helga and Hirschfeld, Ursula

$2000 \quad$ Phonetik lehren und lernen. München: Langenscheidt. Hirschfeld, Ursula

1994

Untersuchungen zur phonetischen Verständlichkeit Deutschlernender. (Forum Phoneticum, Bd. 57). Frankfurt/M.: Hector. 
2003 Phonologie und Phonetik in Deutsch als Fremdsprache. In: Claus Altmayer and Roland Forster (eds.), Deutsch als Fremdsprache: Wissenschaftsanspruch - Teilbereiche - Bezugsdisziplinen, 189233. Frankfurt/M etc.: Peter Lang.

Hirschfeld, Ursula, Heinrich P. Kelz and Ursula Müller (eds.)

2002

Phonetik international. Grundwissen von Albanisch bis Zulu. Ein Online-Portal: www.phonetik-international.de. Waldsteinberg: Heidrun Popp Verlag.

Hirschfeld, Ursula and Kerstin Reinke

1997 Simsalabim. Übungskurs zur deutschen Phonetik (Video, Kassette, Arbeitsbuch). München: Langenscheidt.

Hirschfeld, Ursula and Eberhard Stock (eds.)

$2000 \quad$ Phonothek interaktiv (CD-ROM). München: Langenscheidt.

Kohler, Klaus J.

1995 Einführung in die Phonetik des Deutschen. 2nd edition. Berlin: Erich Schmidt Verlag. 
